\title{
Aortic incompetence in pauciarticular juvenile chronic arthritis
}

\author{
R G HULL, M A HALL, AND A N PRASAD
}

Canadian Red Cross Memorial Hospital, Taplow

SUMMARY An 8 year old girl with seronegative pauciarticular onset juvenile chronic arthritis who developed progressive joint destruction and aortic incompetence is presented.

Cardiac involvement is a rare complication of juvenile chronic arthritis. Pericarditis is the most common form and is seen predominantly in systemic onset disease. ${ }^{12}$ Pericardial and valvular abnormalities have also been reported in seropositive juvenile rheumatoid arthritis, ${ }^{3}$ while aortic incompetence is occasionally seen in juvenile ankylosing spondylitis. Involvement in pauciarticular pattern disease, in which four or less joints are affected in the first three months, is rare. ${ }^{4}$ We report the case of an 8 year old girl with pauciarticular onset juvenile chronic arthritis who has developed progressive destructive joint involvement and gross aortic incompetence, presumably due to aortitis.

\section{Case report}

A girl born in May 1976 after a normal pregnancy presented at the age of 7 months with a swollen ankle; biopsy at her local hospital showed an inflammatory arthritis. Over the next six months the left third finger, left fifth finger, and the right ankle became involved. She was treated with aspirin but became progressively immobile so that in July 1977 oral prednisolone (10 $\mathrm{mg}$ on alternate days) was started.

She was first referred at the age of 3 years 1 month, in June 1979, when additional features were an erythematous rash lasting for the previous two days and four episodes of unexplained fever, each lasting 48 hours. There was no personal or family history of psoriasis or seronegative spondyloarthropathy.

Examination showed involvement of the left third and fifth proximal interphalangeal joint together with the left third and fifth flexor tendons in the hands, and severe limitation of movement in both hind feet at the ankle, subtalar, and midtarsal joints. Slit lamp examination of the eyes was and remains normal. She was on the third centile for height and the 10th centile for weight.

Investigations yielded the following results: haemoglobin $116 \mathrm{~g} / \mathrm{l}$; white blood count $13 \cdot 2 \times 10^{9} / 1$ (neutrophils $76 \%$, lymphocytes $24 \%$ ); erythrocyte sedimentation rate $40 \mathrm{~mm}$ in the first hour; IgA $2 \cdot 8$ $\mathrm{g} / \mathrm{l}$, IgG $13.4 \mathrm{~g} / \mathrm{l}$, and IgM $1.9 \mathrm{~g} / \mathrm{l}$; antinuclear antibody 100 units with homogenous pattern; and HLA type A1, A2, B8, B44, Cw5,-, and DR3,-.

She received appropriate physiotherapy, night splintage, and continued treatment with naproxen and prednisolone. In June 1980 a systolic murmur was first noted; there was no associated anaemia. Over the next three and a half years her disease remained active in the affected joints and other joints. The knees, cervical spine, left wrist, and the right first interphalangeal joint became progressively involved, despite three years of treatment with sodium aurothiomalate $(1 \mathrm{mg} / \mathrm{kg} /$ week $)$ and later D-penicillamine $(15 \mathrm{mg} / \mathrm{kg} /$ day $)$.

In December 1983 her general practitioner commented on a systolic murmur at the apex, and a chest $x$ ray film at that time yielded normal results. She continued to have an active destructive arthritis, and in November 1984 signs of aortic incompetence were first observed. There was a palpable systolic thrill associated with an aortic ejection murmur and a pronounced left ventricular impulse. There was a loud early diastolic murmur of aortic incompetence. At the apex an Austin Flint murmur was audible. The pulse at 100 beats per minute was collapsing in nature. Corrigan's sign was present with a blood pressure of $120 / 40 \mathrm{~mm}$ of mercury. There was no evidence of cardiac failure. As before, severe involvement of her hind feet with ankylosis, flexion deformities of the knees, and synovitis of several small hand joints were present.

The haemoglobin had dropped to $96 \mathrm{~g} / \mathrm{l}$ with anisocytosis and hypochromia, the white blood count was $14.6 \times 10^{\circ} / 1$ (neutrophils $79 \%$ ), platelets $572 \times 10^{9} / 1$, and the erythrocyte sedimentation rate was $52 \mathrm{~mm}$ in the first hour; the urea was $4 \cdot 0$ $\mathrm{mmol} / \mathrm{l}$, with normal electrolyte concentrations and a 24 hour urinary protein of $0 \cdot 3 \mathrm{~g}$. Blood cultures and throat swab yielded negative results, antistreptolysin-O titres were less than 80 units $/ \mathrm{ml}$, and microscopy and culture of a midstream urine yielded negative results. $C$ reactive protein was $90.4 \mathrm{mg} / \mathrm{l}$ (normal range less than $8 \mathrm{mg} / \mathrm{l}$ ) and $\mathrm{IgG}$ $16 \cdot 3 \mathrm{~g} / \mathrm{l}, \operatorname{IgA} 3.4 \mathrm{~g} / \mathrm{l}$, and $\operatorname{IgM} 1.7 \mathrm{~g} / \mathrm{l}$. The chest $x$ ray film showed moderate cardiomegaly with enlargement of the left ventricle. The electrocardiogram 
showed left ventricular hypertrophy but no ST changes. A cross sectional echocardiogram was consistent with free aortic incompetence and showed a large dilatated left ventricle. The aortic valves appeared normal, but the aortic root was dilatated. A Doppler study confirmed aortic incompetence without other valve disease or coarctation of the aorta.

In the absence of nodules or endocarditis it was considered that the valve lesion was secondary to aortitis. In view of the probability of active aortitis and progressive joint destruction, treatment with chlorambucil $2 \mathrm{mg}$ daily was started and treatment with prednisolone increased to $10 \mathrm{mg}$ and $2 \mathrm{mg}$ on alternating days. At follow up in January 1985 she had improved generally and gained weight. The erythrocyte sedimentation rate had fallen to $25 \mathrm{~mm}$.

\section{Discussion}

This is the first case of aortic incompetence in pauciarticular juvenile chronic arthritis in this unit. Cardiac involvement is well described in the systemic pattern of disease. ${ }^{12}$ Clinical pericarditis is seen in about $10 \%$ of patients, while postmortem studies show a high incidence of $45 \% .^{1}$ In addition, a true myocarditis accompanying pericarditis and also valvular damage has been described, ${ }^{2}$ but this feature is unusual and, if present, minimal. Valve damage is also seen in seropositive juvenile rheumatoid arthritis ${ }^{13}$ and is associated with severe destructive articular disease and a high titre of rheumatoid factor. The valve cusps become infiltrated, eroded, and deformed by nodules. Aortic incompetence is also a well recognised complication of juvenile onset spondylitis as a result of aortitis.

Our patient falls into none of these categories. She has pauciarticular, seronegative, and HLA-B27 negative disease. Her fevers were not thought to be a manifestation of systemic juvenile chronic arthritis, the fever being low grade and sustained rather than high and remittent. Kramer et al described the case of a woman with isolated aortic involvement and a monoarthritis of her knee progressing to polyarthritis with iridocyclitis; ${ }^{6}$ but this patient had had a systemic presentation two years previously.

The differential diagnosis in this child included infective endocarditis, coarctation of the aorta, and rheumatic fever. These were excluded as far as possible by the appropriate investigations described above. The diagnosis of aortitis was made by exclusion, there being no evidence to support an infective, acute rheumatic, or nodular aetiology in the absence of active disease. Treatment with gold and penicillamine failed to control the arthritis both clinically and radiologically, and in view of the life threatening nature of the cardiac lesion and the progressive destructive nature of the arthritis, treatment with chlorambucil was justified. Valve replacement presents particular technical difficulties in a small child in the presence of active aortitis, ${ }^{5}$ and as she is well compensated at present, possibly protected by her immobility, surgery has been deferred.

We thank Dr B M Ansell for permission to publish this case and also acknowledge the valuable advice of Drs $J$ Pcarce. $\mathrm{R}$ Blackwood, and $\mathrm{K}$ Hallidic-Smith.

\section{References}

I Brewer EJ. Juvenile rheumatoid arthritis-cardiac involvement. Arthritis Rheum 1977;20:231-6.

2 Svantessan H, Bjorkhelm G, Elborg R. Cardiac involvement in juvenile rheumatoid arthritis. Acta Paediatr Scand 1983;72: 345-50.

${ }^{3}$ Leak AM, Millar-Craig M. Ansell BM. Aortic regurgitation in sero-positive juvenile arthritis. Ann Rheum Dis 1981;40:229-34.

4 Ansell BM, Wood P. Classification of juvenile chronic polyarthritis. In: Munthe E, ed. The care of the rheumatic child. Eular Bulletin, Monograph Series No 3. Basel: Eular Publications, 1978:42-50.

${ }^{5}$ Williams WG, Pollock JC, Geiss DM, Truster TA, Fowler PS. Experience with aortic and mitral valve replacement in children. J Thorac Cardiovasc Surg 1981;81:326-33.

6 Kramer PH, Imboden JB, Waldman FM, Turley K, Ports TA. Severe aortic insufficiency in juvenile chronic arthritis. $A m \mathrm{~J}$ Med 1983;74:1088-91.

Correspondence to Dr R G Hull, Wexham Park Hospital, Slough, Berkshire SL2 4HL, England.

Received 9 January 1986 